\title{
Darwinism and Environmentalism
}

\author{
BRIAN GARVEY
}

A number of authors have combined a commitment to Darwinian evolution as a major source of insight into human nature with a strong commitment to environmentalist concerns. The most notable of these is perhaps Edward O. Wilson, in a series of books. ${ }^{1}$ Yet it may appear that there is a tension between Darwinism as a world-view - or least some major aspects of it - and a concern for non-human entities as worthy of concern in their own right. In the present paper, I want to address some of the reasons for thinking there is such a tension.

Firstly, it might be thought that Darwin has taught us that the relationship between different species is intrinsically antagonistic, and moreover that this antagonism is what drives evolutionary change itself. Thanks to the popular iconography associated with Darwinism, we tend to think of the process of evolution as being primarily natural selection, and of natural selection as a 'struggle' or 'competition' between creatures, where one creature's gain is inevitably another's loss. Moreover, we tend to think of different species, not just individuals of the same species, as in struggle or competition against each other. The popular iconography often portrays this struggle as incessant, so that the day-to-day life of creatures is seen as one of 'kill or be killed', 'eat or be eaten'. This would not in itself show that we should not be concerned about non-human entities, at least not without committing the fallacy of 'is' implies 'ought'. Nor would it even show that it is impossible for us to be so concerned. But it would suggest that, in being so concerned we would be somehow sailing against the wind of evolution, either against the process itself, or against inbuilt tendencies that it has produced in ourselves, or both. Consequently, if we wanted a basis for our environmentalist concerns, we would have to find it somewhere other than in evolution. In this paper, I will attempt to show that this view of evolution is highly misleading, and at best gives us only a very partial picture.

1 See for example Edward O. Wilson: The Future of Life (London: Abacus, 2002); Brian Baxter: A Darwinian Worldview: Sociobiology, Environmental Ethics and the Work of Edward O. Wilson (Aldershot: Ashgate, 2007). 


\section{Brian Garvey}

But that, by itself, will not tell us anything about whether, or to what extent, we should care about the non-human environment. As regards this issue, there are two basic positions: (1) Deep ecology is the view that non-human entities - such as animals, trees, and even, in more extreme versions, inanimate objects such as hills or islands - have moral standing in themselves. ${ }^{2}$ That is, they are entitled to certain types of treatment, or we have certain duties towards them, irrespective of any benefits that they confer on us humans. That is not to say that the moral standing of these non-human entities overrides that of humans. In deciding what to do, there may, consistently with deep ecology, be a trade-off between benefit to humans and benefit to other things. The key point is that the moral standing of non-human entities is not derived from that of humans: it is not just because they benefit us that they deserve our moral consideration. (2) The opposing view to this is instrumentalism as regards the nonhuman environment: the view that we only have obligations to any non-human entity insofar as it affects us, and that those obligations are entirely dependent upon and derived from our obligations to humans. My aim in this paper is not to defend deep ecology, or indeed to settle the issue between deep ecology and instrumentalism one way or another. Rather, I am attempting to show that what counts as being of instrumental value to humans is rather more than may sometimes be thought. That is, even if we accept the arguments for instrumentalism, we still ought to have a great deal of concern for preserving the environment. The difference between deep ecology and instrumentalism in practice may be very little. At the very end of the paper, I will also (tentatively) suggest that a purely instrumental attitude to the environment is not really possible. So I suggest a position somewhere between deep ecology and instrumentalism.

Someone who argues for an instrumentalist position on scientific, and specifically evolutionary, grounds, is Richard Lewontin. According to Lewontin, the idea that we should save the environment, or even that there is an environment independent of us for us to be concerned about, is fundamentally misguided. This is because he thinks there is no such thing as the environment: there are only the environments of different types of creatures, which are partially but inextricably constituted by the activities of those creatures and which we, like any other living thing, cannot help but alter to suit ourselves. If this is so, he argues, then the idea that any

2 See Arne Næss: Ecology, Community and Lifestyle: Outline of an Ecosophy. Translated by D. Rothenberg (Cambridge: Cambridge University Press, 1989). 
non-human entity has moral standing independent of our interests makes no sense. Thus, Lewontin concludes, any programme of conservation must perforce be subservient to human interests. I wish to address Lewontin's arguments here.

\section{The image of evolution as ruthless competition}

What implications does Darwinism have for our attitude towards the environment? At first sight, it might look as though Darwinism is not friendly towards environmental concerns. Darwinism is often thought to paint a picture of ruthless competition between, as well as within, species. This, in turn, may be thought to encourage a view of the environment as something to be exploited for self-interested gain. Darwin himself did not use the expression 'survival of the fittest' until the fifth edition of The Origin of Species. But he did use the expressions 'preservation of favoured races' (as part of the full title of The Origin of Species) and 'struggle for existence' (the title of Chapter 3). What is beyond doubt is that the association between on the one hand the terms 'Darwinism', 'natural selection' and even 'evolution' itself, and on the other the image of ruthless competition between organisms, is powerful and deeply ingrained, in the minds both of the general public and of many scientists. Indeed, the dissemination of Darwin's theory, and of its present-day updated and corrected version (though there is some disagreement as to exactly what that is), often strongly reinforces that association.

I am not about to embark on a lengthy spree of Dawkins-bashing, and I will later argue that some of Dawkins' supposedly more sophisticated opponents are equally guilty of distortions. But it must be admitted that the until-recently Professor for the Public Understanding of Science has been culpable in this regard. In his TV programmes The Root of All Evil? and The Genius of Charles Darwin, Dawkins introduces the concept of natural selection to the accompaniment of images of a cheetah chasing down and killing an antelope, a spider devouring a fly, and so forth. The voice-over, meanwhile, informs us that natural selection is a process in which the general law is eat or be eaten, kill or be killed:

As night falls, it's kill or be killed. ... During the minute it takes me to say these words, thousands of animals are running for their lives whimpering with fear, feeling teeth sink into their throats, thousands are dying from starvation or disease, or feeling a parasite rasping away from within. There is no central authority, no 


\section{Brian Garvey}

safety net. For most animals the reality of life is struggling, suffering, and death. ${ }^{3}$

Dawkins often describes nature itself as 'ruthless', 'pitiless' and so forth, and he is not alone in this. One thing that might be - and has been - said about this type of language is that it is unduly anthropomorphic. An impersonal natural process cannot be ruthless or pitiless, because it is not the kind of thing that can show mercy (ruth) or pity at all. We might as well say that the process is immoral or has bad taste, as opposed to being something to which the concepts of morality and taste just do not apply. Some people worry about this anthropomorphic language more than I do. ${ }^{4}$ We use metaphors all the time, and this does not seem to me to be in itself problematic, even in science, as long as we know how to cash the metaphors out in literal terms. And in this instance, the literal meaning of what Dawkins is saying seems clear enough: other metaphors for the same thing include: it is a zero-sum game, one creature's gain is another's loss, etc. Essentially, Dawkins is saying that, as a general rule, when one creature's chances of surviving and reproducing are increased, it is by means of another creature's chances of surviving and reproducing being decreased.

Prior to giving a response, I would like to suggest that there are two different things that Dawkins might be saying. Firstly, he might be talking about the products of evolution; that is, he might be saying that what evolution produces, as a general rule, is creatures that are constantly engaged in zero-sum games against each other. Or, secondly, he might be talking about the process of evolution; that is, he might be saying that evolutionary change is predominantly produced by the accumulation of zero-sum games. (This is of course assuming that he takes natural selection to be the predominant producer of evolutionary change, but he clearly does, and has said so on many occasions. ${ }^{5}$ ) At times, it looks as though Dawkins is only making the second claim. In The Selfish Gene, ${ }^{6}$ he goes to great lengths to explain that natural selection, though in itself 'ruthless' and 'pitiless',

'The Genius of Charles Darwin', Channel 4, November 2008.

For Example Mary Midgley 'Gene-Juggling' Philosophy, vol. 54 (1979) 439-58; Lynn Margulis and Dorion Sagan: Acquiring Genomes: A Theory of the Origins of Species (New York: Basic Books, 2002).

5 For Example Dawkins: 'Universal Darwinism' in D.S. Bendall, ed. Evolution from Molecules to Man (Cambridge University Press). Reprinted in Hull and Ruse, ed, The Philosophy of Biology (Oxford University Press, 1998).

6 Second Edition (Oxford University Press, 1989). 


\section{Darwinism and Environmentalism}

can and often does produce behavioural tendencies that are co-operative (reciprocally beneficial) or altruistic (self-sacrificing for the benefit of others). However, the behavioural tendencies of which he speaks are always between members of the same species: an individual may co-operate with another individual of the same species for reciprocal benefit; an individual may sacrifice itself for the benefit of another of the same species. So it is not clear whether he thinks cooperation or altruism between members of different species are possible, or at all common, outcomes of evolution. It may be, for all he tells us, that they are only very rare, aberrant, outcomes. The general rule for how creatures fashioned by evolution behave towards each other is: eat or be eaten, kill or be killed.

Now, straight away, and without having to reach for exotic, unfamiliar examples, it can be said that this is at best an extremely partial picture of what goes on between organisms of different species in the natural world. Only some animals are carnivores. If he intended to illustrate a perfectly typical product of evolution, Dawkins could have shown us an image of a monkey eating a banana. Not only does the monkey not kill the banana tree by eating the banana; the banana being eaten is in fact the means by which the banana tree produces offspring in the wild. More generally, herbivorous animals very often play this vital role for the plants they feed on - seed distribution. An extremely common pattern is that the seeds are passed out in the faeces of the animal, and the faeces provide a nutrition-rich base from which a new plant can grow. So the animal gets a meal, the plant gets a chance to reproduce - it is reciprocal benefit, not zero-sum. The same is true of bees pollinating plants. It could be added that even carnivorous animals cannot wipe out the animals on which they prey.

But there is a deeper story here, one that has begun to be revealed in the work of Lynn Margulis and others. Margulis became famous for her hypothesis about the origins of the eukaryotic cell, a hypothesis that is now generally accepted, and about which I will say more anon. Margulis argues that mutually beneficial relationships between creatures of different species are in fact all-pervasive, and that what we often think of as a single organism is usually a collection of organisms of different kinds. ${ }^{7}$ The most obvious example of this is lichens, which consist of algae and fungi (and often bacteria as well) living in symbiosis. The algal component and the fungal component can in fact live separately, but when they are together, as is the norm,

7 Lynn Margulis: Symbiotic Planet: A New Look at Evolution (New York: Basic Books, 1998). 


\section{Brian Garvey}

they share functions rather than duplicating them. But examples of such symbiotic relationships can be found much closer to home, and much more pervasively. Moreover, they are often found to involve much deeper integration than in the lichen case: it is precisely because the two components are not all that deeply integrated that the dual nature of lichens was discovered so relatively early. Cows are renowned for their possession of multiple 'stomachs', and for the process of pre-digestion that one 'stomach' (more properly called the rumen) performs before the cow chews it again and it then food enters the stomach proper. But this process of preparing the cow's food for digestion is carried on in the rumen by a vast array of micro-organisms. The rumen provides a nutrition-rich environment for the micro-organisms, and they in turn play a vital role in enabling the cow to digest. Bacteria in our own intestines perform analogous functions for us, and Margulis estimates that about 10\% of our bodies by dry weight consists of such friendly bacteria. A more dramatic example can be found in termites. Up to $30 \%$ of their body mass is made up of bacteria which enable to them to digest wood. Within cells themselves, a similar situation can be found. What we might think of as a single cell often contains component parts that have their own separate DNA, thus being in that sense separate organisms. But they are tightly integrated with their hosts in situations of reciprocal benefit. Margulis has argued that the flagella of many bacterial cells may have evolved from separate entities (although this hypothesis is not widely accepted). So, while predation and parasitism do exist - situations in which one creature's gain is another's loss there is no reason to think it is the norm of what evolution produces.

But what about the process of evolution? Recall that Dawkins believes that natural selection is the prime producer of evolutionary change. He is by no means alone in this. Darwin himself wrote that 'I am convinced that Natural Selection has been the main but not exclusive means of modification.' 8 To be fair to Darwin, however, even he makes clear, in the chapter with this title, that the term 'struggle for existence' not only should not be taken as implying any intention on an organism's part, but also should not be taken as entailing that one creature only gains out of another's loss. He says, for example, that a plant on its own at the edge of a desert may be said to be struggling for existence - even though the only things that threaten it are the inanimate physical conditions around it:

8 Darwin, Charles (1859): The Origin of Species. Reprint of the First Edition, W.J. Burrow, ed. (Harmonsworth: Penguin, 1968), 69. 
Two canine animals in a time of dearth, may be truly said to struggle with each other which shall get food and live. But a plant on the edge of a desert is said to struggle against the drought, though more properly it should be said to be dependent on the moisture. ${ }^{9}$

Admittedly, this must be set against his remark about natural selection being the primary driving force, for selection is between creatures and other creatures, not between creatures and their inanimate surroundings. However, our knowledge of evolution has grown since Darwin's time. Think again about the herbivores and the plants they feed off. How did these arrangements come about in the first place? In many cases, the fruit, and the herbivore's ingestive and digestive apparatus are evolved to fit each other. The herbivores did not find the fruit ready-made in its current form - they coevolved. Likewise with bees and flowers. There is an (unintentionally) amusing video, easy to find on YouTube, made by two 'creation scientists', Kirk Cameron and Ray Comfort, entitled 'The Banana The Atheist's Worst Nightmare'. The presenters point out in great detail how extremely well designed bananas are for being eaten by humans. But there is nothing whatsoever paradoxical about this. If we assume that our ancestors have been eating bananas for a long time - which seems extremely likely, given that both humans and our nearest relatives chimpanzees are very fond of bananas - then we have been co-evolving with bananas for a very long time. Of course they are well-designed for being eaten by us! (Given that human hands, mouths, and digestive organs are suited to a very wide variety of different tasks and food-types, it is likely that it was bananas that did most of the adapting to us or our distant ancestors, rather than the other way round. We have also been selectively breeding them for many centuries now, to make them easier for us to eat.)

But once again, such cases of obvious co-evolution are just the tip of a huge iceberg. Margulis has a radical new view on how evolutionary novelties, and in particular new species, arise. ${ }^{10}$ Consider again those micro-organisms that live inside the bodies of termites, cows, and us. Note that in every case the micro-organisms perform functions that are useful, and in many instances indispensible, to the hosts. But at some point in the past the ancestors of the micro-organisms must have entered the ancestors of the hosts, and hence before that they must have been able to live separately. So when the

10

Ibid., 116.

Margulis: Acquiring Genomes. 


\section{Brian Garvey}

micro-organisms entered the hosts it must have triggered a process of co-evolution, a process by which both parties gained.

The importance of such processes of symbiosis-followed-by-coevolution for bringing about major evolutionary change can be seen most strikingly in the origin of eukaryotic cells. Eukaryotic cells are cells that contain a nucleus containing DNA, and other organelles e.g. mitochondria, chloroplasts - which contain their own separate DNA. The cells of all animals, fungi and plants are eukaryotic. We tend to think of the DNA in the nucleus as 'the' genes of an individual. And it is true that a lot of genetic research has focussed on the DNA that gets recombined in sexual reproduction. We are familiar, for example, with the fact that if your father carries some rare recessive gene (e.g. the cystic fibrosis gene) then the chances that you also carry it are $50 \%$. But that is because your nuclear DNA is inherited from your mother and your father. By contrast, the DNA in your mitochondria is inherited only from your mother. So if your mother carries some rare mitochondrial-DNA gene, then - barring mutations - the chances of you also carrying it are 100\%. Margulis' hypothesis, now generally accepted, was that these organelles carry their own separate DNA because they were once separate organisms. ${ }^{11}$ The transition from bacteria to eukaryotic cells involved the coming together into mutual beneficial symbioses of different types of cells, and that relationship became progressively more tightly integrated. The ancestors of (e.g.) our mitochondria entered into a symbiotic relationship with other cells, and have since co-evolved with them. Thus, the great increase of cellular complexity that made possible the existence of all plants, fungi and animals happened because cells of different kinds formed symbiotic relationships - co-operative partnerships, if you will-and then co-evolved to be tightly integrated units functioning as one.

I offer one final, (literally) colourful example: green animals. As you may remember from your high school biology, green plant cells have chloroplasts but animal cells don't, and it is by means of chloroplasts that plants photosynthesise. Chloroplasts, like mitochondria, have their own DNA, and so are almost certainly descended from what were once separate organisms. The simpler varieties of green algae are in fact quite similar to chloroplasts, except that the latter don't perform all their life-sustaining functions for themselves, instead relying on other parts of the cells they are in to do so. So in all likelihood ancestral proto-plants assimilated green algae in some way.

11 Lynn Margulis: Symbiosis in Cell Evolution (San Francisco: W.H. Freeman, 1981). 
This implies that green plants did not themselves evolve the ability to photosynthesise: rather, they incorporated organisms that had already evolved it. What is less well known is that there are also some animals that contain chloroplasts, and are in consequence green and able to photosynthesise. For example, green slugs such as Elysia viridis can go without food for as long as nine months; instead of eating they bask in the sun in shallow waters. They ingest green algae, but do not digest them; instead they incorporate them into their tissues where they remain alive and active. This, too, must result from co-evolution between the algae and the slugs.

Even if one is sceptical about Margulis' more all-embracing claim about symbiosis being the driving force of evolution, there is no doubt that it has been responsible for some of the most important transitions. So there is no reason to think of the process of evolutionary change as essentially involving zero-sum games, or kill-or-bekilled. It is just as likely to be brought about by the setting up of situations of reciprocal benefit between organisms of different species. Likewise as regards evolution's products: evolution does not invariably produce creatures whose interests are antagonistic to each other. It also produces creatures, very often of different species, who work together for reciprocal benefit. Consequently, there is nothing intrinsically anti-evolutionary in working to help other species. The fact that we have evolved does not imply that we have an inbuilt tendency to be antagonistic towards other living things.

\section{Lewontin and the challenge to Deep Ecology}

A second challenge to environmentalism from evolutionary theory comes from someone who has been one of Dawkins' severest critics over the last thirty years and more: Richard Lewontin. While Dawkins sees the relationship between different species as intrinsically antagonistic, and such antagonism as essential to evolutionary change, Lewontin claims that the environment does not exist. He says that 'the growing environmentalist movement to prevent alterations in the natural world that will be, at best, unpleasant and, at worst, catastrophic for human existence cannot proceed rationally under the false slogan "Save the Environment". The environment does not exist to be saved.' ${ }^{2}$ Rather, he thinks, "what we can do is

12 Richard Lewontin: The Triple Helix: Gene, Organism and Environment (Cambridge, Massachusetts: Harvard University Press, 2000), 67-8. 


\section{Brian Garvey}

try to affect the rate of extinction and direction of environmental change in such a way as to make a decent life for human beings possible.' 13 In other words, we can nurture, preserve, and shape the world in a way that best serves human interests.

Such a view flies in the face of deep ecology - the view that nonhuman entities have moral standing in themselves. Lewontin's view of our obligations towards the non-human world is an instrumentalist one, as the above quotations make clear.

How does Lewontin argue for this view? The key point he is arguing is that there is no such thing as the environment tout court. That is, what counts as constituting the environment depends on the type of creature you are, and hence different types of creature, even in the same physical place, will have different environments. We should not think of the world as containing pre-existing niches into which creatures come and adapt themselves. As Lewontin sometimes likes to express it, a world without living things would contain no niches, no environments. This breaks down into two points:

(1) Niche construction: Any living creature, simply by existing, will physically alter its immediate surroundings.

(2) Biological Kantianism: Not everything in the physical surroundings of an organism is relevant to it at all, and the same thing in the same physical surroundings may have different relevance to different organisms.

(1) Niche construction: The first point is most obviously true if we consider cases such as the following. Trees create a canopy that changes the temperature, humidity and lighting conditions beneath it in a dramatic way. Termites build vast (nine metres high in some cases) mounds, thus providing for themselves a mini-world whose temperature, humidity and lighting are highly regulated and significantly different from what they are outside. Beavers build dams that alter the flow of rivers. But Lewontin's argument does not depend on the recitation of individual examples. His point is that any living creature is constantly taking in matter from its surroundings and giving out matter to its surroundings. It cannot but alter them. Similarly, every living creature gives off or takes in heat, so that the temperature of the zone immediately around its body is something other than it would be were the creature not there. For example, we humans carry around with us an envelope of air that is constantly regulated by the heat of our own bodies: it is the temperature of this air that we are used to. In temperate climates such as Britain's, this means 
that our air-envelope is usually warmer than the air would be if we weren't there. This explains why wind makes us feel cold - it momentarily deprives us of our warm envelope. There can, then, be no talk of us, or any other organism, leaving the environment unaffected. Simply by being alive in it, we are altering it.

Moreover, it is this altered environment - altered, that is, by the creature's own presence within it - to which any creature is adapted. It is common to think of the environment as something that exists prior to a given creature living in it, and of the creature as becoming adapted to that environment. It is true that evolution happens because the morphologies of organisms are malleable, and are changed in response changes to the physical surroundings. But what Lewontin wants to emphasise is that the physical surroundings are also malleable, and any living creature perforce changes them just by living in them. Living creatures in general are, as a result of evolution, well-suited to the physical surroundings they live in. But that is not just because they have altered themselves, or been altered, to accommodate to living in those surroundings: it is also because they have themselves altered the surroundings. In some cases (e.g. the termites) they have altered them to produce a niche that suits their needs; in others, they have produced effects as an inevitable consequence of their activities. But in either type of case, the world to which they are suited to live in is not one that existed prior to them. The ambient temperature in which humans feel comfortable is the one produced by our own bodies. And termites doubtless have evolved functions that their ancestors didn't have before they lived in mounds, and lost ones they had. The consequence of all this, then, is that the world we humans live in is a world that we have made. This is true not just of the obvious technology that we have made, but of the grass and the very air that surrounds us. And it is a world to which we are suited. There can be no talk of us making a world that is free of our alterations, and in any event such a world would be impossible for us to live in.

(2) Biological Kantianism: But Lewontin's second point is more radical. He argues that not only do creatures inevitably alter their physical surroundings, but that the physical surroundings do not in themselves constitute the creature's environment. To begin with, we can take the environment to mean that to which a creature is adapted, or which poses a problem to which it needs to adapt. If we do so, then two different types of creature (e.g. different species) living in the same physical surroundings - even taking into account the changes that they both have made to those surroundings - will, according to Lewontin, be in different environments. The reason 


\section{Brian Garvey}

for this is that the entities around them will have different significances for one than for the other. 'Significance' here just means 'the difference something makes'. But the difference something makes to any creature will vary depending on the type of creature it is. For example, a piece of woodland may contain a plant that is a nutritious food for one creature, a deadly poison to another. So, although one and the same plant is in the two creatures' physical surroundings, different things are in their respective environments. Different challenges or opportunities are presented to different creatures by the same plant. Similarly, objects in the physical surroundings may have importance for one creature, but none for another. Lewontin gives the example of a water boatman, a long-legged insect that lives on the surface of ponds. For this creature, the surface tension of water is a significant feature of the environment, something that it is obliged to cope with in a way that we humans are not. Moreover, for a smaller creature that dwells on the surface of water, such as the microscopic paramecium, surface tension is a more significant feature of the environment than gravity. Lewontin also mentions the thrushes and phoebes in his garden. Thrushes use small stones to break open snails' shells, but for a phoebe the stones might as well not be there. For one creature, a particular object in its surroundings is of supreme importance. For another, the same object does not exist; it is no part of its environment at all.

A consequence of this view is that a creature can never have direct access to all the things that are in its physical surroundings. It has access to things that are of relevance to it - as dangers, opportunities, obstacles - insofar as they are of relevance to it. Moreover, there is no reason to think that humans are a special case: we are, it is true, exceptionally hungry for information - i.e. we gather information well beyond immediate or even possible utility. But we do so using sense organs and cognitive apparatus that have been shaped through and through by past evolution. There is no reason to think that every bit of our physical surroundings is accessible to or understandable by us, even with all the prosthetics in the world. Ultimately, we can be aware only of what affects us. Affecting us may only mean exciting our curiosity, but our curiosity is a feature of minds shaped by past evolution. ${ }^{14}$

14 For an elaboration of this consequence of Lewontin's view, see Matthew Ratcliffe: 'An Epistemological Problem for Evolutionary Psychology', International Studies in the Philosophy of Science 19 (1) (2005), 47-63. 
Hence, on Lewontin's view, we can only be concerned for the environment insofar as it affects humans, which would be bad news for any deeper ecological views. However, Lewontin's point can be turned around: not only is the environment partially constituted by the organism; the organism is partially constituted by its environment. This implies, or so I will argue, that in damaging its environment an organism is damaging itself. In fact, Lewontin's arguments, far from negating this point, actually reinforce it. As some of the examples already mentioned illustrate, creatures shape their surroundings and in turn are shaped by their surroundings. In fact, it is a little misleading to say 'and in turn' since it is an ongoing, cyclical process of reciprocal effects. We make our niches (but, it should be emphasised, not out of nothing) and we ourselves change to fit into those niches. Similarly, if we take Lewontin's biological Kantian point, it too cuts both ways. This is not just because organisms adapt to their environment, but because the development of an organism requires a particular type of environment to go smoothly, or indeed at all. This is part and parcel of the wisdom of developmental biology. It is generally admitted that genes play a key role in shaping the development of any organism, but they do not shape it on their own. Any developing organism depends on resources from its surroundings to develop. If those resources are not there, or are different, the organism will fail to develop normally, or at all. So just as there is no environment without an organism, neither is there any organism without an environment. An organisms' environment - delicate as it is, and partially made and constituted by the organism as it is - is part of the organism.

This point can be taken further by drawing on something else that Darwin taught us. All of earthly life is one family. We all, from bacteria and archaea to petunias, platypuses and people, are descended from one common ancestor. In fact, a host of discoveries in different areas of biology have revealed that the kinship goes far deeper than Darwin suspected. The unravelling of the genomes of different creatures has revealed that there is far less genetic variety than we might have thought. For example, the genes involved in building eyes in fruit-flies are the same as those involved in building human eyes. Moreover, recent work in evolutionary developmental biology has revealed previously unsuspected deep structural similarities across a wide spectrum of living things: widely different species can be thought of as combinations of the same basic kit. And the work that Margulis pioneered reveals that the very cells in our bodies, as well as those of other animals, fungi and plants, contain the descendants of what were once separate living creatures, with most of 


\section{Brian Garvey}

their genotypes still intact. We once thought of evolution as a diverging tree of life, but, because many major evolutionary changes were produced by organisms assimilating other organisms in symbiotic relationships, it might be better to think of it as a web whose strands converge as well as diverge. If we trace our ancestry via our nuclear DNA alone, then we are descended from single-celled organisms called archaea. These archaea were ultimately descended from bacteria. But the bacteria that were the ancestors of our mitochondria diverged from the archaea before they joined up with archaea to form the closely co-operating collectives we call eukaryotic cells. We are clearly descended from archaea, but should we say that we are descended from our mitochondria's free-living predecessors as well? Or should we just say that our mitochondria themselves are? Our mitochondria are part of us in a very strong sense, a stronger sense, for example, than the symbiont micro-organisms that live in our digestive systems. We could stipulate that only our nuclear DNA counts as far as ancestry goes, so we are descended from archaea and not from our mitochondria's free-living ancestors. But the motivation for doing it does not seem very strong. In just what sense are we our cell nuclei but not our mitochondria? Noam Chomsky once remarked that if alien linguists landed on Earth, they might think that all human languages were one language. In a similar vein, I suggest that if alien geneticists landed on Earth, they might be impressed by the genetic similarity between all its living creatures: might they think that we were all one kind?

The overall picture that emerges is of an environment which has shaped, and been shaped by, terrestrial life as a whole. A view of the natural world as in a strong sense 'ours', where this means belonging to life as a whole, makes good sense in the light of evolution. What I suggest is that we should learn to look on the Earth as our home in a very deep sense: it is the home we-all living creatures - have made for ourselves, and to which we have become adapted. Think of armchair into which indentations have been formed by our sitting in it over many years. It has been, entirely unconsciously, shaped by us to suit us. But now imagine that a whole host of things in our surroundings have been so shaped, and that we have in turn been shaped by them, so that they fit us and we fit them. Our 'environment', I want to suggest, is like this. What we think of as the 'natural' environment is in fact a collection of things in our surroundings that we have shaped and to suit us. We can make this point at bigger or smaller magnitudes. It has been suggested that the movement of the Earth's tectonic plates is a result of the action of living organisms at the thermal vents at the bottom of the sea, so that the distribution 


\section{Darwinism and Environmentalism}

of the continents is due to living things. And it is not even controversial that all the free oxygen in the Earth's atmosphere is there because of green plants and algae. The blue-green ball with whose appearance from outer space we are all familiar would look very different if living things had not been acting on it for billions of years. If we are willing to think of all of life as 'us', then we should look at that blue-green ball and say: that is our home, which we made. If we are not prepared to go that far, we can focus our attention more narrowly, and think about the world that is our - that is, humans' - home. Our ancestors evolved in African savannah, and the niche that we adapted to and ourselves shaped contains the familiar 'natural' features grass, running water, trees, and so forth. This was the home that we made for ourselves and adapted ourselves to long before we built stone houses. Edward O. Wilson has frequently pointed out that people are happier in a world that has grass, running water etc. We should not think of such a world as 'natural', if natural means in contrast to a human world. It $i$ s the human world, far more than the world of technological 'conveniences'. We tamper with it at our peril. I will let Wilson speak here:

It is ... possible for some to dream that people will go on living comfortably in a biologically impoverished world. They suppose that a prosthetic environment is within the power of technology, that human life can still flourish in a completely humanized world, where medicines would all be synthesized from chemicals off the shelf, food grown from a few domestic crop species, the atmosphere and climate regulated by computerdriven fusion energy, and the earth made over until it becomes a literal spaceship rather than a metaphorical one, with people reading displays and touching buttons on the bridge. ${ }^{15}$

But he warns against such a view:

To disregard the diversity of life is to risk catapulting ourselves into an alien environment. We will have become like the pilot whales that inexplicably beach themselves on New England shores. ${ }^{16}$

Wilson defends this view in part by appealing to the potential obviously instrumental uses to which things in the environment can be put. E.g. by driving species to extinction, we might inadvertently

15 Edward O. Wilson: The Diversity of Life, Second Edition (Harvard: Belknap, 1999), 347.

16 Ibid., 346. 


\section{Brian Garvey}

lose a chance of discovering cures for all kinds of illnesses. But I would like to think that he is saying more than this here: he is saying that a world with significantly reduced species diversity world would be a world in which human life would be greatly impoverished - would be an inhuman world. And let us not forget that a world with significantly reduced biological diversity is something that we are currently in serious danger of creating.

I tentatively suggest, then, a position somewhere in between the deep ecology and instrumentalist positions. A purely instrumentalist attitude towards the non-human world, I claim, makes no sense. The environment is part of us, as much as our arms and legs are, and we can no more take a purely instrumentalist attitude towards the environment than we can towards ourselves. But the deep ecology approach presupposes that the non-human environment can have a good that is independent of our good. On an optimistic view, there need be no conflict between an instrumentalist attitude towards the environment and a deep ecology one, once they have both been modified to take into account how evolution actually works, and how organisms, including us, relate to their/our environment.

Lancaster University 